\title{
TERRITORIO Y PSICOLOGÍA SOCIAL Y COMUNITARIA, TRAYECTORIAS/IMPLICACIONES POLÍTICAS Y EPISTEMOLÓGICAS ${ }^{1}$
}

\author{
TERRITÓRIO E PSICOLOGIA SOCIAL E COMUNITÁRIA, TRAJETÓRIAS E \\ IMPLICAÇÕES POLÍTICAS E EPISTEMOLÓGICAS \\ TERRITORY AND SOCIAL AND COMMUNITY PSYCHOLOGY, POLITICAL \\ AND EPISTEMOLOGICAL PATHS/IMPLICATIONS
}

http://dx.doi.org/10.1590/1807-03102016v28n3p484

Santiago Conti

CONICETy Universidad Nacional de Rio Negro, San Carlos de Bariloche/Río Negro, Argentina

\begin{abstract}
RESUMEN
"Territorio" es un concepto originado en el campo disciplinar de la Geografía, que a lo largo del siglo XX ha ido reformulándose según las distintas corrientes del pensamiento social. Es factible reconocer que en la actualidad dicho concepto ha trascendido su ámbito disciplinar y es utilizado profusamente en el campo de las ciencias sociales, en general, y en la Psicología Social y Comunitaria, en particular. Trascendiendo el encuadre disciplinar de la geografía, el presente trabajo se propone realizar un recorrido analítico para comprender las implicancias políticas y epistemológicas que supone el uso del concepto "territorio" para la Psicología Social y Comunitaria. Se sostendrá que lejos de lo que los recortes disciplinares efectúan, "territorio" es un concepto que no está ni ha estado alguna vez exento de determinados supuestos psicosociales; supuestos que desde el presente artículo serán evidenciados considerando las íntimas relaciones entre las disciplinas en cuestión.
\end{abstract}

Palabras clave: territorio; psicología social; psicología comunitaria; interdisciplina.

\section{RESUMO}

"Território" é um conceito originado no campo disciplinar da Geografia, que ao longo do século XX foi reformulado de acordo com as diferentes correntes do pensamento social. É possível reconhecer que hoje este conceito transcendeu seu campo disciplinar e é usado extensivamente no campo das ciências sociais em geral e na Psicologia Social e Comunitária, em particular. Transcendendo o enquadramento disciplinar da Geografia, este trabalho propõe uma viagem analítica para compreender as implicações políticas e epistemológicas envolvidas no uso do conceito "território" para a Psicologia Social e Comunitária. Argumentamos que longe de cortes disciplinares, "território" é um conceito que não é, nem nunca foi, isento de determinados pressupostos psicossociais; pressupostos que neste artigo serão evidenciados considerando as relações íntimas entre as disciplinas envolvidas.

Palavras-chave: território; psicologia social; psicologia comunitária; interdisciplina.

\begin{abstract}
"Territory" is a concept originated in the disciplinary field of Geography, and that throughout the twentieth century has been reformulated according to the different frameworks of social thought. It could be said that, at present time, the concept has transcended its disciplinary field and is been used extensively in the field of social sciences in general, and in particularly, social psychology. Skipping the disciplinary framework, this paper proposes an analysis to understand the political and epistemological implications involved in using the concept of "territory" for the Social and Community Psychology. It will be argued that, far from what disciplinary approaches does, "territory" is a concept that is not and has not ever been exempted from certain psychosocial assumptions; Assumptions that from the present paper will be evident considering the intimate connections between the disciplines involved in it.
\end{abstract}

Keywords: territory; social psychology; community psychology; interdiscipline. 


\section{Introducción}

Referir al concepto territorio requiere hoy de un conjunto de precisiones complementarias o accesorias, situación muy distinta a la que se daba hace 50 años. Las ciencias sociales han cambiado, como así lo denotan los nuevos objetos de estudio y el bagaje conceptual que a ellos refiere. En este contexto teórico cambiante, el interrogarse por la Psicología Social y Comunitaria actualmente demanda incorporar indefectiblemente una conceptualización (inter y multidisciplinaria ${ }^{2}$ ) del territorio.

La mudanza dada en las ciencias sociales no es ajena a procesos políticos y epistémico-filosóficos (entre otros) de distintas escalas, como lo ha sido la caída del régimen Soviético o las políticas del Consenso de Washington, así como los efectos propiciados por el llamado "giro lingüístico" o la sociología del conocimiento, entre otros enfoques científicos. Tampoco se puede obviar el contexto sociocultural y político que viene imponiendo una nueva agenda del "desarrollo" para América Latina, lo cual ha llevado a una reactualización de lo territorial en tanto articulación de viejas y nuevas demandas y conflictos. La globalización como macro-proceso político, económico y cultural así como los modos de re-primarización económica en América Latina evidencian la superposición de territorialidades en disputa en escenarios locales, donde los actores no confrontan exclusivamente "cara-a-cara". Desde aquí, los territorios y las herramientas analíticas tienen que ser repensados, interpelados.

De modo general, se ubica al territorio como una conceptualización cuyo tránsito por las ciencias sociales ha ido desde extremos objetivistas hacia abordajes que incorporan lo subjetivo y relacional en tanto dimensiones constitutivas del mismo.

En las ciencias sociales, en general, y en la psicología social en particular, se ha incorporado el uso del concepto territorio, para dar cuenta de diferentes fenómenos en su relación con la espacialidad y su dimensión social. Considerando este hecho el presente trabajo se propone realizar un recorrido analítico para comprender las implicancias políticas y epistemológicas que este concepto ha adquirido bajo la mirada de distintas concepciones teóricas. El objetivo que nos proponemos no es de índole prescriptiva sino analítica, pues busca ofrecer una orientación que facilite la operacionalización conceptual de territorio según los compromisos político-epistemológicos que cada interesado/a decida asumir.

\section{¿Por qué hoy nos interrogamos por el territorio desde la Psicología Social y Comunitaria, habiendo sido éste un concepto fundante de la Geografía moderna?}

Para responder esta pregunta cabe esbozar una aproximación siguiendo el recorrido señalado por Milton Santos en 1990 en su libro Hacia una Geografia Nueva. En este escrito el autor dirige su mirada crítica hacia las denominadas Geografía del Comportamiento y la Geografía de la Percepción, según señala ambas disciplinas son reduccionistas al analizar la construcción del espacio desde una "escala" individual ${ }^{3}$. Si bien por un lado resalta como novedad el hecho de que "lo espacial" sea abordado desde la forma en que los individuos interpretan y organizan el espacio de modo singular, en contraposición con tendencias que intentaron aplicar un modelo espacial para un conjunto poblacional; por otro lado se diferencia de la idea de una definición de cada espacio social para cada individuo.

El aspecto central destacado por el autor refiere a que por más que la "escala" sea individual, no es adecuado soslayar otras diferencias y jerarquías relativas a la producción del espacio tales como las dimensiones económicas, de género, históricas, entre otras, y que se despliegan y analizan a diferentes escalas. Según Santos, los usos y apropiaciones individuales del espacio, o sea, la construcción de lugares, se da en el marco de experiencias y tramas colectivas, lo cual supera el abordaje comportamental caracterizado por el encuadre individual; por otro lado, su crítica al modelo de la percepción concluye que la dimensión histórica-estructural es condicionante de cualquier proceso perceptivo atravesado por determinaciones simbólico-ideológicas.

Es interesante retomar el planteo teórico de Milton Santos ya que en él vemos cómo los desarrollos en una disciplina, en este caso la Geografía, no están ni han estado alguna vez exentos de determinados supuestos psicosociales (epistemológicos y políticoontológicos) que sin explicitarlo permiten evidenciar las íntimas relaciones entre disciplinas.

Ahora bien, a fin de comprender qué territorio se nos es ofrecido contextualmente para discutir desde la Psicología Social y Comunitaria, es necesario identificar las corrientes teóricas que adoptan al territorio como concepto y poder comprenderlo desde su amplia dimensión categorial. El geógrafo Alejandro Benedetti (2011) ofrece un análisis matricial intentando organizar los recorridos de este concepto, que a los fines de este trabajo serán 
considerados como principales dos matrices: la que clasifica la conceptualización del territorio como espacio absoluto o como espacio social, por un lado; y por otro el territorio en clave material, denominada perspectiva materialista, o en clave integradora, denominada perspectiva integradora.

La conceptualización del territorio como espacio absoluto refiere a una ontología física, cerrada y continente del territorio: es aquel soporte real que sirve de base para la vida humana, definido (y definible) objetivamente, y con una clara distinción entre elementos naturales y sociales. Esta conceptualización es propia de la geografía clásica, y desde la matriz o perspectiva materialist ${ }^{4}$ se pueden reconocer las concepciones naturalistas, de corte positivista y determinista, que fue la base para las tradiciones etológica y jurídico-política del territorio. Desde estas perspectivas se consolidó la geopolítica clásica como una geografía del Estado.

Desde la etología, se subsume el comportamiento humano al estudio sistemático animal en cuanto a su despliegue innato y espacial para su reproducción (con influencia del darwinismo). Ahora bien, desde la tradición jurídico-política se incorporó la escala nacional e internacional bajo una concepción biogeográfica, que se fundamentaba desde una visión organicista del Estado: el espacio vital humano-animal como fundamento de una geografía del Estado. Su instrumentalización influyó en la geografía militar, en la cartografía, en la escuela, en la formación ciudadana, entre otros contextos. De este modo, el territorio se concibe en términos de jurisdicción (competencia y funciones) sobre las que se aplica una acción, la acción estatal. Dentro de la perspectiva materialista se reconoce también la tradición marxista clásica en tanto el territorio se figura como la base material de los recursos de los que se vale la sociedad. Al mismo tiempo es condición de la reproducción material de la sociedad. De este modo, estos enfoques presentan la decisión político-epistémica de priorizar la unidad de análisis o escala "nacional"; y el territorio (el límite, la frontera) en su definición en tanto objetividad espacial, y se caracterizan por un vacío analítico de sociabilidad.

Consecuentemente, y al mismo tiempo siguiendo una cronología, serán las conceptualizaciones del territorio como espacio social las que brindarán (de distinta manera) ángulos de inteligibilidad para el reconocimiento y la comprensión de la acción humana/social en la conformación o configuración de determinados tipos de territorios. Inmediatamente es posible entrever que serán estas perspectivas las que, según quien escribe, nos invitan a repensar el territorio desde la Psicología Social y Comunitaria -
PSC. Aquí serán otros enfoques que se caracterizarán por plantear una interrelación compleja y diferenciada de los procesos sociales, espaciales, políticos e históricos.

La transición entre los modelos objetivistas y aquellos que incluyen ciertos determinantes subjetivos en la conformación territorial es ubicada por Benedetti a partir del trabajo The Significance of Territory de Jean Gottmann, quien desde un enfoque humanista plantea:

territorio, a pesar de ser una entidad muy importante, material, medible y concreta, es el producto y la expresión de las características psicológicas de los grupos humanos. De hecho, es un fenómeno psicosomático de la comunidad, que está repleto de conflictos internos y contradicciones aparentes ${ }^{5}$. (Gottmann, 1973, citado en Benedetti, 2011, p. 28)

Si bien Benedetti lo ubica como un planteo de transición, para quien escribe y considerando los antecedentes recientemente expuestos, esta definición representa un salto cualitativo considerable, y un corrimiento hacia la determinación social del territorio ampliamente novedosa. Un actor, en este caso identificado como "la comunidad", en tanto "grupo humano" es productora de territorio. En esta definición destaca la heterogeneidad interna, que Gottmann identifica como la conflictividad interna y las contradicciones aparentes. En tal sentido podría pensarse en un modelo biopsicoterritorial, una tensión cartesiana, o incluso en una antigua clave en la tensión materia-idea.

Por otra parte, en dicho planteamiento se expone una concepción de cuerpo como una entidad material, medible y concreta, y el aporte de lo psicológico (lo ideativo), conflictivo y contradictorio propio de los "grupos humanos". Ahora bien, cabe destacar que el grupo humano o la comunidad identificada por Gottmann aporta, en su expresión territorial, su conflictividad interna, lo cual permitirá luego contrastarla con otros modelos, que incorporarán otras variables o localizaciones de conflicto. De todos modos, se advierte que esta concepción no supera la naturaleza legal y jurisdiccional de una "porción del espacio" definido a escala nacional como territorio (Benedetti, 2011; Schneider \& Peyré Tartaruga, 2006). Es decir, el marco o escala se ajusta a la dimensión jurisdiccional (espacial y estatal) establecida como soporte físico y legal de determinada expresión territorial, correspondiendo con lo que sería una geopolítica "humanizada".

Cabe reconocer la filiación biológica del abordaje "humanista". Partiendo del concepto de 
territorialidad, propio de la etología en los inicios del siglo XX, donde el peso de lo innato fue central para comprender su reproducción en tanto conjunto de adaptaciones que los animales realizan para controlar y definir un territorio (material). De modo similar, fueron cuestiones de identidad, seguridad y estímulo las que motivaron los estudios sobre territorio desde la perspectiva humanista, donde también existe la correspondencia entre territorio y área espacial o terreno.

La clave analítica subjetiva de dicha definición de territorio se apoya menos en una conflictividad o disputa territorial entre actores y más bien encuentra soporte en un abordaje de las formas de representación y expresión espacializada de procesos de un individuo o comunidad. Igualmente cabe el reconocimiento de las formas diferenciadas en que distintos grupos conciben su territorio, y en este punto cabe el parafraseo de Silveira (2011) en tanto un mismo territorio es posible de ser representado como un recurso para un grupo (humano), mientras que otro puede concebirlo como "un abrigo".

El territorio se comienza a definir como un espacio social a partir de la concepción de múltiples y complejas tramas sociales, donde es "lo social" lo que permite comprender el espacio. Esta forma de definir el territorio ha implicado la proliferación de estudios sobre este tema donde las dimensiones a analizar no se reducen en la dicotomía natural-humano, sino que en tanto construcción social tomaron relevancia los estudios económicos, culturales, políticos del territorio, entre otros.

Dado el carácter que fueron adquiriendo los estudios sociales Benedetti (2011) se refiere al territorio desde una perspectiva integradora. Bajo esta óptica se consideran diferentes ejes, pero serán las relaciones sociales las que fundamenten y den forma a los territorios. Conceptos como "poder", "territorialidad", "conflicto", "actores", entre otros, serán parte de una amplia y heterogénea matriz de inteligibilidad de los procesos socioespaciales.

En el análisis propuesto por Benedetti (2011) son considerados aquellos ejes que definen el territorio teniendo como base la comprensión de los fenómenos comunitarios y sus dinámicas de espacialización. E este sentido el autor cita cuatro enfoques: el relacional, el geocrítico, el regional-político y el territorial. Considerando esto es posible adelantar, a fin de justificar esta ligación entre la categoría territorio y la PSC, que es esta perspectiva la que se considera ofrece mayor referencialidad analítica para los procesos psicosociales que acontecen en contextos comunitarios, que son los que atañen a esta subdisciplina.
El enfoque geocrítico tuvo un importante despliegue en la "renovación" de territorio. De raíces marxistas, aunque incorporando miradas de otras perspectivas, su principal exponente latinoamericano es el brasilero Milton Santos. Su propuesta enfatiza la idea de que toda teoría del espacio se vincula directamente con una teoría social y por tanto el territorio debe ser comprendido como un hecho social; mientras que el espacio lo presenta en tanto complejo, multidimensional, que no precede a la sociedad ni es resultado de ésta, sino que se presenta como una instancia social.

Según lo propuesto en el párrafo anterior el territorio (y su dimensión espacial) es una construcción social, y por tanto brinda inteligibilidad sobre "los usos sociales" de lo espacial. Aquí ya el territorio no es exclusivamente un soporte material, sino que es también la materialidad misma de las construcciones sociales y sus disputas simbólico-materiales, que ciertamente constituyen la base para su (re)producción (Santos, 1990, 1994, 2000).

El concepto de "rugosidad" (Santos, 1990), irrumpió para tensionar la relación tiempo-espacio, al definir el espacio en términos de acumulación desigual de registros socioespaciales históricos, cargados de conflictividad. Hacia el final de su itinerario analítico, tal como plantea Zusman (2002), esta relación tiempoespacio se vio influenciada por sus discusiones en el marco de la teoría de la estructuración (tensión estructura-agencia) a partir de la interacción entre sistemas de objetos y de acciones.

La incorporación del concepto "rugosidad" destaca el carácter activo del agente inmerso en sistemas de relaciones que lo preexisten y sobre las cuáles actúa. En este sentido se establece una diferencia basada en la comprensión de la acción desde fuerzas externas o exclusivamente estructurales. Al mismo tiempo que incorpora a la comprensión del espacio los conceptos de "horizontalidad" (relaciones espaciales próximas) y "verticalidad" (relaciones espaciales distantes) (Santos, 2000) para dar cuenta de la multidimensionalidad y multiescalaridad de la acción y los agentes involucrados en la construcción del territorio.

Si bien gran parte de los abordajes de dicho enfoque priorizan las escalas más bien regionales, interesa a los efectos del presente trabajo no sólo mencionar que han problematizado el territorio y las dinámicas centro-periferia en relación al capitalismo y a la globalización (Harvey, 1996; Sassen, 2003), así como cuestiones de índole cultural, sino también destacar cómo la matriz analítica refiere a la objetivación de una configuración social particular a partir de 
actores que disputan el espacio. Dicha objetivación es dinámica pero al mismo tiempo histórica, es decir, su historicidad se conceptualiza como rugosidades, y como expresa Santos (1990) en la siguiente cita, es de carácter testimonial, es un lenguaje relativo a los modos de producción:

El espacio es la materia trabajada por excelencia. Ninguno de los objetos sociales tiene tanto dominio sobre el hombre, ni esta presente de tal forma en la vida cotidiana de los individuos. (...) El espacio, por lo tanto, es un testimonio; atestigua sobre un momento de un modo de producción por la memoria del espacio construido, de las cosas fijadas en el paisaje creado. (Santos, 1990, pp. 153-154)

En las preocupaciones por los modelos territoriales globalizadores, la orientación se centra en la generación de vínculos que tiendan a la horizontalidad como un modo de defensa y resistencia territoriales de las comunidades ante el avance de proyectos verticales, que tienden hacia relaciones de subordinación (Santos, 1994). Este eje propuesto por Santos presenta una clara relación con una de las preocupaciones centrales de la PSC que es la de la construcción de proyectos de comunidad que tiendan hacia procesos de autonomización, donde sean los recursos e ideas comunitarias los que sean la base de legitimidad de dichos proyectos, intentando neutralizar las lógicas de subordinación tanto externas, como incluso las internas, es decir, aquellas que atraviesan las propias subjetividades de la comunidad (Cf. Montero, 2008)

El recorrido para comprender el "giro" en la definición de territorio, así como sus supuestos psicosociales, continua reconociendo los aportes pioneros de Claude Raffestin y Robert Sack en la denominada concepción relacional del territorio.

Raffestin (1980/1993) aborda en su obra clásica Por una geografía del poder una crítica central a lo que entiende era la óptica unidimensional (y vertical) de la geografía, donde es el poder estatal en sus distintas escalas lo que define el territorio. Al mismo tiempo aporta una concepción multipolar del poder, fundamentado en relaciones sociales, cuyas acciones concretas y simbólicas se objetivizan y expresan espacialmente definiendo territorios.

Raffestin evidencia un corrimiento que supera el modelo estadocéntrico y permite la teorización y análisis de otros tipos o formas de conflictos. Estas "Geografías del poder" abrevan en teorizaciones foucaultianas del poder, concibiéndolo como un aspecto inmanente a las relaciones sociales, y cuya escala de análisis es local, regional, de modo que habilita un abordaje "botton-up" o "desde abajo" respecto a la organización social del espacio. Lo espacial, y para nuestro interés, el territorio adquiere al mismo tiempo una dimensión temporal, dinámica, lo que permitió desde este enfoque concebir territorialidades móviles, temporales, territorialidades en proceso.

Será la propuesta de Raffestin la que evidenciará más claramente el lugar activo del "sujeto" en la construcción del territorio, un territorio socialmente construido a partir del lenguaje, de la capacidad semiótica, apoyado de poderes multipolares y de carácter dinámico. El territorio existe, según Raffestin, en tanto que espacio semiotizado:

El territorio es una reordenación del espacio cuyo fin se encuentra en los sistemas de información de los que dispone el hombre, en tanto que perteneciente a una cultura. El territorio puede ser considerado el espacio informado por la semiósfera. ... De este modo, yo voy a considerar la cuestión de la ecogénesis territorial en tanto que un proceso de semiotización del espacio. (Raffestin, 1986, pp. 177-180)

La obra de Robert Sack Human Territoriality (1986) se la ubica como otro aporte fundante del enfoque relacional. En ésta revisita el concepto de "territorialidad" despegándose de la base innatista de los abordajes previos de la escuela humanista, para concebir la territorialidad como la “... estrategia de un individuo o grupo de afectar, influir o controlar personas, fenómenos y sus relaciones, a través de la delimitación y ejerciendo control sobre un área geográfica. Esta área puede ser denominada territorio" (Sack, 1986, p. 17, citado por Benedetti, 2011).

Según muestran diversas traducciones, Sack entiende la territorialidad como estrategia o como intento (o tentativa) de un actor, sea este individual o grupal. La distinción no resulta significativa para el caso que se ocupa, mas lo que cabe empezar a despuntar es el criterio de racionalidad subyacente: Sack aquí ubica una acción voluntaria y conciente (de control, influencia, afectación), una estrategia deliberada, de un sujeto con motivaciones, objetivos y deseos, desplegada en una superficie. De aquí se entiende que territorio es toda área que es susceptible o tácticamente delimitada y controlada por un actor, a partir de su influencia hacia otros. Esta explicación refiere claramente a un modelo analítico en el que a partir de mecanismos de control, influencia, entre otros, se está haciendo referencia al vector "poder" como aspecto constitutivo de las relaciones sociales y su territorialidad. Por otro lado, cabe destacar que este tipo de territorios son territorios definidos "desde el interior y desde la perspectiva de quien lo 
define" (Benedetti, 2011, p. 45) lo cual implica la delimitación de una exterioridad, un otro, un afuera en la construcción y control del territorio "propio" (Manzanal, 2007).

Según lo señalado vemos que el modelo adoptado por Sack evidencia que la construcción de un territorio requiere de un concepto jerárquico y controlador del poder, caracterizado por relaciones de inclusión/exclusión, apropiación/expropiación, insinuando más un modelo de producción de territorio a partir de lógicas de control.

Por otra parte, el denominado por Benedetti enfoque relacional tuvo y tiene varios continuadores y exponentes. Entre ellos se destacan los aportes de los geógrafos brasileros Marcelo Lopes de Souza y Rogério Haesbaert. López de Souza se ha especializado en estudios del territorio y del desarrollo, y ha surcado el camino de los estudios relacionales del territorio al postular que el territorio refiere a las relaciones de poder en su delimitación y demarcación espacial (Souza, 1995, p. 78). El vector "poder" propuesto se presume multiescalarmente, y no sólo en su dimensión político-económica, sino en su determinación culturalsimbólica y psicosocial. En este punto, concibe a la "identidad" como una construcción social que articula y aglutina sentidos, promueve identificaciones, en tanto formación psicosocial en que el poder se inteligibiliza al tiempo que en su cualidad territorial, se espacializa.

Ahora bien, será Haesbaert quien, para evitar caer en esencialismos, apoya dicha concepción despegando cualquier asociación fija entre espacio e identidad, y sosteniendo que de lo que se trata es de dar cuenta de "identidades territoriales". Este posicionamiento, de tipo relacional, muestra que el territorio no es un continente en el cual se encuentran "identidades", acabadas, homogéneas, etc., sino que al concebir la dimensión identitaria en perspectiva socioconstruccionista éstas se redefinen constantemente (con algunos aspectos más fijos y otros más móviles) y sus territorialidades son una tensión constante de dichos procesos.

Siguiendo a Lefevre, entendemos que son las relaciones de poder de dominación (proceso de tipo concreto, funcional, ligado a las ideas de "posesión" o "propiedad") y de apropiación (de tipo simbólicas, subjetivas) las que constituyen los territorios. El autor afirma que "O território, imerso em relações de dominação e/ou de apropriação sociedade-espaço, "desdobra-se ao longo de um continuum que vai da dominação político-econômica mais 'concreta' e 'funcional' à apropriação mais subjetiva e/ou “cultural-simbólica"” (Haesbaert, 2004a:95-96, citado por Haesbaert, 2007). Esta definición que entiende el poder y el territorio como constitutivos de las relaciones sociales resulta una tesis interesante para fundamentar el locus politico $^{8}$ de la PSC. Siguiendo a Montero podemos citar a seguir una de sus primeras definiciones:

estudio de los factores psicosociales que permiten desarrollar, fomentar y mantener el control y poder que los individuos pueden ejercer sobre su ambiente individual y social para solucionar problemas que los aquejan y lograr cambios en esos ambientes y en la estructura social'. (Montero, 2008, p. 70)

El enfoque regional político-cultural (concebido también como "nueva geografía regional") adopta como escala de análisis "la región". De esta manera se preocupa por las manifestaciones sociales en un espacio entendido como regional, y desde el campo analítico social, aborda las formas de representación de lo regional, de lo fronterizo, así como los sentimientos ligados a la pertinencia, valoración y reivindicación de los lugares; esto implica una concepción construccionista y dinámica del espacio, como territorios en construcción, donde lo simbólico y lo cultural tienen una parte constitutiva de las identidades regionales y políticas y sus dinámicas de espacialización.

Benedetti aclara que en tanto función heurística territorio y región serían equivalentes funcionales (2009), al punto que lo regional se desdobla, sin dejar de reconocer criterios políticos y técnicos clasificatorios "externos" (aquellos que indican "esto es una región"), en una dimensión subjetiva de lo territorial a partir de conceptualizar procesos de conciencia regional, ideas e identificaciones de región y sus simbolismos a partir de la función narrativa ${ }^{10}$.

El último enfoque a delimitar es el denominado enfoque territorial. A este respecto cabe aclarar que está de "moda" en los distintos campos de análisis o intervención social; en muchos casos se lo utiliza como sinónimo de "territorio" (Rozas, 1999), y en algunos de ellos, se evidencia un uso acrítico o contradictorio en tanto se sustraen los supuestos subyacentes. Se destaca como un enfoque al que se le ha dado un uso práctico o instrumental en el marco de los programas de gestión del desarrollo, una aplicación extendida en las periferias y semiperiferias del mundo, predominante en enfoques de reducción de la pobreza, a partir de las líneas de financiamiento y promoción de organismos internacionales como el BID, la FAO, el Banco Mundial, la CEPAL.

Dicho territorio se convierte en una unidad operativa económica que presenta, según Schejtman 
y Berdegué (2004), 7 características: competitividad, innovación tecnológica, carácter sistémico, demanda externa al territorio, vinculación urbano-rural, desarrollo institucional y relacionalidad-identidad socialmente construida. Estas características orientan una gestión del desarrollo a partir de una acción territorial (donde territorial refiere a un área o espacio delimitado) destinada a modificar relaciones sociales de determinada población.

Lo que se intenta generar a partir de la concepción de una unidad operativa económica es transformar las condiciones de incorporación al mercado, a partir de "un principio de progresividad de objetivos, en escala de orden de menor (construcción de capital humano y capital social) a mayor complejidad (eliminación de la pobreza, modificación de las relaciones de poder, profundización de la democracia)" (Schejtman \& Berdegué, 2004, p. 41). Este enfoque territorial destaca el papel principal que tiene la escala local en tanto protagonista de las acciones y procesos del desarrollo. De este modo, en numerosas ocasiones se presenta como un modelo metodológico-operativo del abordaje de la pobreza, y de aquellas relaciones que impiden o limitan la competitividad del territorio en términos de su incorporación a la lógica del mercado (Barsky \& Schejtman, 2008). Esta propuesta se encuentra en sintonía con las transformaciones institucionales y políticas orientadas a la descentralización del gobierno por parte del Estado, así con modelos de planificación botton-up o ascendente (Boisier, 1999). Asimismo, Boisier incorpora una mirada crítica respecto de qué tipo de territorios interesan gestionar desde el desarrollo y sostiene que:

se trata de un concepto asociado a la idea de contenedor y no a la idea de contenido. Territorio es todo recorte de la superficie terrestre, pero no cualquier territorio interesa desde el punto de vista del desarrollo. ... Así es que la expresión "desarrollo territorial” se refiere a la escala geográfica de un proceso y no a su sustancia. (Boisier, 1999, p. 8)

La propuesta del enfoque territorial entiende que es la gestión no-inteligente de las capacidades locales la que reduce la competitividad del territorio, lo cual al menos en su postulación podría implicar que se trata más bien de ingeniería territorial de las relaciones sociales, generada a partir de todos los actores que se encuentren dentro de cada territorio. De este modo, el territorio es siempre un activo a desarrollar, y donde la racionalidad técnica es más adecuada que la racionalidad política (Lapalma, 2001) para encauzar procesos de aprendizaje social territorial, de innovación tecnológica y desarrollo institucional.

\section{¿Conclusiones? Orientaciones}

A lo largo del escrito se ha intentado evidenciar las implicancias de las distintas trayectorias del concepto territorio en su apertura categorial, es decir, en sus diversas adscripciones y compromisos teórico-políticos dentro de las ciencias sociales. En lo que respecta al interés disciplinar de la Psicología $\mathrm{y}$, particularmente, de una Psicología Social y Comunitaria (PSC), se destaca el uso conceptual de territorio como categoría psicosocial y relacional.

La noción de territorio es frecuentemente referenciada en la Psicología Social y Comunitaria. $\mathrm{Su}$ uso ha quedado indiscutiblemente ligado a la conceptualización de "comunidad" y "sentido de comunidad" (McMillan \& Chavis, 1986). Ahora bien, una revisión ampliada de estas conceptualizaciones ha permitido identificar que su utilización frecuentemente se realiza de modo indistinto en la literatura de nuestra disciplina, dando principal uso al concepto "territorio" en tanto porción de tierra (base material), o jurisdiccional, dando equivalencia funcional a conceptos como territorio, barrio, zona, nivel local, lo local (Berroetea, 2007; Christlieb, 2000; Krause, 2001; Montero, 2008; Vidal, 1991). Ello no implica que dichas lecturas sobre el modo de concebir el "territorio" deban ser descartadas ni mucho menos, puesto que ellas definitivamente responden a la praxis histórica de nuestra disciplina, tanto en la concepción del "territorio" desde un punto de vista comunitarioorganizacional (desde abajo), como desde un punto de vista de delimitación espacial en el marco de determinada política (gestión) de intervención, desde arriba (Rozas, 1999).

A partir de las matrices propuestas por Benedetti, se ha ofrecido un análisis centrado en los supuestos psicosociales de la categoría territorio desde los distintos usos conceptuales que se han hecho en las tradiciones del pensamiento geográfico. Esto ha permitido dar cuenta de cuan imbricadas están las zonas de contacto entre tradiciones del pensamiento geográfico y modelos psicosociales inscriptos en la Psicología.

La relevancia, según quien escribe, reside en la contemporaneidad del concepto territorio, que deviene una "moda", o más bien un uso categorial en disputa que queda asociado a procesos identitarios, a posiciones estratégicas, en el marco de un escenario de conflictividad y a proyectos en tensión, que obligan a reflexionar sobre el lugar de las comunidades en el marco de una globalización hegemónica y desigual (Wiesenfeld, 2006). 
El uso y apropiación de concepto de territorio por parte de distintos actores, así como una consecuente articulación con otros conceptos, tales como "desarrollo", "comunidad", "sustentabilidad", "identidad", entre otros traen como resultado, un conjunto de discursos, de lenguajes en pugna. Esto se evidencia, por ejemplo, en la forma estratégica (no necesariamente "racional") en que algunos organismos de desarrollo, y los gobiernos, han aplicado este concepto, así como tambien en la forma en que las propias comunidades locales se han apropiado del concepto de territorio en el marco de una tensión entre la horizontalidad y la verticalidad del poder.

Una manera de graficar dicha tención se expresa en las situaciones que se presentan en los casos de grupos migrantes o comunidades desplazadas, que debido a causas diversas, sean económicas, o de violencia física o por conflictos armados, o desastres naturales, experimentan territorialidades móviles, temporales, o en proceso de reterritorialización, o que aplican para otras tantas comunidades que debido a proyectos ajenos no pueden "devenir" o resolver sus demandas y derechos territoriales (esto se evidencia claramente alrededor de la disputa territorial de comunidades expuestas a lógicas de explotación y proyectos extractivistas y de gran escala, en diversas zonas y regiones de América Latina). El compromiso de la Psicología Social y Comunitaria con estas problemáticas, de opresión y desigualdad, ha estado enunciado desde los albores de la perspectiva Latinoamericana (Freitas, 1998; Montero, 2008).

Desde quien escribe, se opta por concebir la configuración de grupos/comunidades junto a diversos modos de inscripción espacial, entendibles como territorio, desde el enfoque relacional. Desde aquí se entiende que las configuraciones grupales, comunitarias, sea por sus atravesamientos o por su dinámica interna, son factibles y necesarias de analizarse en clave multiescalar. Por lo tanto, los procesos de territorialidad implican tramas de sentidos y prácticas con múltiples desdoblamientos, que configuran un posicionamiento (siempre político) de cada experiencia en las formas, opciones y elecciones que adopta su construcción territorial.

Coincidimos con el planteo de Rogério Haesbaert (2007) respecto a la relación entre identidad y territorio, donde reconocer los procesos de territorialidad a partir de la propia historicidad del control/dominio del territorio (territorios instituidos) que antecede y funciona como condición de posibilidad de la dinámica identitaria de cada experiencia. Es decir un abordaje de las formas, opciones y elecciones, un locus, que combina por un lado de los registros- vivencias así como la articulación de dichos registros desde la configuración de la experiencia actual. Aquí el concepto de "identidades territoriales" planteado por Haesbaert se destaca por su potencial heurístico, entendiendo que las mismas se dan indistintamente en casos de control y no control de un territorio ${ }^{11}$.

En complemento al enfoque indicado en el párrafo anterior desde la Psicología Social y Comunitaria, interesa recuperar el concepto de rugosidad elaborado por Milton Santos (1990). Según éste, las rugosidades se inscriben testimonialmente en tanto "el hombre trabaja sobre su herencia" (Santos, 1991, p. 155), y refieren a la historicidad del espacio-tiempo en sus relaciones de poder (de producción), desiguales, "entre las instituciones, las empresas y los hombres" (Santos, 1991, p. 94). Su vinculación a las "identidades territoriales" refiere a una articulación coyuntural que ofrece o habilita la inscripción y actualización de dichas rugosidades en la construcción relacional de determinada arena política (Long, 2007).

Acorde a la recapitulación teórica que hemos realizado, vemos que al des-esencializar la construcción del territorio desde una perspectiva psicosocial y centrada en una comunidad, se advierte que dicha construcción no se apoya exclusivamente en un locus común, por fuera de todo cambio, sino que la misma se soporta en simultáneo y desde distintas escalas, a partir de actores y posiciones externas (otros), cuyos proyectos también refieren a otras construcciones de territorio, a formas de espacialización del poder y las relaciones sociales, incluya o no a determinada comunidad (Montenegro, Rodríguez, \& Pujol, 2014; Sawaia, 2006).

A modo de resumen, podemos sintetizar en dos niveles el conjunto de discusiones antes propuesto: por un lado el aporte teórico que problematiza la cuestión interdisciplinaria ligada al "territorio", en tanto éste brinda cierta inteligibilidad y favorece la solidaridad entre dos campos disciplinares, que desde tradiciones y caminos distintos, han intentado conceptualizar la espacialidad desde un punto de vista psicosocial; y por otro lado, destacan los aportes de la perspectiva relacional para comprender los procesos de afirmación social, de defensa o de proyección-reivindicación en su devenir y construcción territorial. Este segundo aspecto da cuenta de determinadas herramientas heurísticas en la reflexión sobre la articulación entre lo espacial como inmanente o constitutivo de las relaciones sociales, puntualmente como parte del locus de comunidad, en tanto campo específico de la Psicología Social \& Comunitaria. 


\section{Notas}

1 El presente trabajo es parte de una serie de discusiones elaboradas en el marco de la Tesis de Maestría en Psicología Comunitaria de la Universidad de Chile. Actualmente forma parte de discusiones ampliadas que se dan en la Tesis Doctoral en Psicología (en curso) de la Universidad de Buenos Aires.

2 Multidisciplinario, en tanto se apela a los distintos campos disciplinares para identificar y seleccionar aquellos tópicos permeables a los cruces en el trabajo interdisciplinario.

3 Se utiliza el término "escala" propio de la Geografía y la Cartografía, cuando desde el campo psicológico se refiere más bien a "nivel de análisis", pero se destaca la equivalencia o compatibilidad para este caso.

4 El uso categorial de la "perspectiva materialista" se vincula en este caso con una ontología física del espacio, evidenciándose la primacía del suelo y lo natural como soporte o base fundamental, escindido de la "dimensión social". Ahora bien, desde quien escribe, se sostiene que $l o$ material no se reduce a lo físico-natural, sino que se opta epistemologicamente por una concepción que entiende la existencia también y en simultáneo de lo material en tanto construcción social (lo social, sea discurso u otro soporte, es base para lo social).

5 El subrayado es de quien escribe.

${ }_{6}$ Le territoire est une réordination de l'espace dont l'ordre est à chercher dans les systèmes informationnels dont dispose l'homme en tant qu'il appartient à une culture. Le territoire peut être considéré comme de l'espace informé par la sémiosphère. ...Cela dit, je vais considérer la question de l'écogenèse territoriale en tant que processus de sémiotisation de l'espace (Raffestin, 1986, pp. 177-180) (traducción del autor).

7 Podemos entonces afirmar que el territorio, inmerso en relaciones de dominación y/o de apropiación sociedadespacio, "se despliega a lo largo de un continuum que va de la dominación político-económica más "concreta" y "funcional" a la apropiación más subjetiva o "culturalsimbólica” (Haesbaert, 2004a, pp. 95-96). (Traducción del autor).

$8 \quad$ Esta idea se emparenta al concepto de "validez psicopolítica epistémica" de Isaac Prilleltensky (2008); se propone su distinción respecto de dar cuenta que la opción por "lo comunitario" de la PSC antecede al criterio de "validez psicopolítica epistémica", al tiempo que lo requiere, pero su posicionamiento discursivo en tanto afirmación le antecede.

9 Montero (2008) refiere que esta concepción de la PSC fue esbozada por su autoría en 1982, y posteriormente reformulada en 1984.

10 Este enfoque se distancia considerablemente del abordaje propuesto para el actual trabajo. Se lo menciona para dar cuenta de su ubicación en el corpus teórico sobre "territorio", y se lo utiliza en situaciones específicas.

11 Haesbaert (2007) sostiene que es factible dar cuenta de identidades territoriales como procesos dinámicos de territorialización, y que eso se da tanto desde la posición del dominio territorial como de la precariedad territorial; lo que no encuentra empírica ni teóricamente posible es concebir un territorio sin territorialidad (desde la óptica que sea, tanto funcional como simbólica).

\section{Referencias}

Barsky, O. \& Schejtman, A. (2008). El desarrollo rural en Argentina: un enfoque territorial. Buenos Aires: Siglo XXI.

Benedetti, A. (2009). Los usos de la categoría región en el pensamiento geográfico argentino. Scripta Nova. Revista Electrónica de Geografía y Ciencias Sociales, 13(286), 1-24. Acesso em 10 de outubro, 2015, em http://www. ub.edu/geocrit/sn/sn-286.htm

Benedetti, A. (2011). Territorio: concepto integrador de la geografía contemporánea. In P. Souto (Coord.), Territorio, lugar y pasaje: prácticas y conceptos básicos en geografía (pp. 11-82). Buenos Aires: Editorial de la Facultad de Filosofía y Letras - UBA.

Berroetea T. H. (2007). Espacio público: notas para la articulación de una psicología ambiental comunitaria. In J. A. Inzunza \& T. H. Berroetea (Eds.), Trayectoria de la Psicología Comunitaria en Chile (pp. 259-285). Valparaíso: Universidad de Valparaíso.

Boisier, S. (1999). Desarrollo (local): ¿de qué estamos hablando? Santiago de Chile: Autor. Acesso em 22 de outubro, 2015, em http://municipios.unq.edu.ar/modules/ mislibros/archivos/29-DesLo.pdf

Christlieb, P. F. (2000). El territorio instantáneo de la comunidad posmoderna. In A. Lindón (Coord.), La vida cotidiana y su espacio-temporalidad (pp. 147-170). Barcelona: AnthroposColMex.

Freitas, M. F. Q. (1998). Elementos para una retrospectiva histórica sobre la psicología social comunitaria en Brasil. In A. Martín (Ed.), Psicología Comunitaria. Fundamentos y aplicaciones (pp. 131-140). Madrid: Síntesis.

Haesbaert, R. (2007). Território e multiterritorialidade: um debate. GEOgraphia, 9(17), 19-46. Acesso em data 10 de outubro, 2015, em http://www.uff.br/geographia/ojs/index. php/geographia/article/view/213/205

Harvey, D. (1996). From Space to Place and Back Again. In Justice, Nature and Geography of Difference (pp. 291-326). London: Blackwell.

Krause, J. M. (2001). Hacia una redefinición del concepto de comunidad. Revista de Psicología de la Universidad de Chile, 10(2), 49-60.

Lapalma, A. I. (2001). El escenario de la intervención comunitaria. Revista de Psicología de la Universidad de Chile, 9(2), 61-70. Acesso em 25 de outubro, 2015, em http://www.revistapsicologia.uchile.cl/index.php/RDP/ article/viewFile/18573/19619

Long, N. (2007). Sociología del Desarrollo: una perspectiva centrada en el actor. México: CIESAS; Colegio de San Luis.

McMillan, D. W. \& Chavis, D. M. (1986). Sense of community a definition and theory. Journal of Community Psychology, 14(1), 6-23.

Manzanal, M. (2007). Territorio, poder e instituciones. Una perspectiva crítica. In M. Manzanal, M. Arqueros, \& B. Nussbaumer (Comps.), Territorios en construcción, Actores, tramas y gobiernos, entre la cooperación y el conflicto (pp. 15-50). Buenos Aires: CICCUS.

Montenegro, M., Rodríguez, A., \& Pujol, J. (2014). La Psicología Social Comunitaria ante los cambios en la sociedad contemporánea: De la reificación de lo común a la articulación de las diferencias. Psicoperspectivas, 13(2), $32-43$. 
Montero, M. (2008) Introducción a la Psicología Comunitaria. Buenos Aires: Paidós.

Prilleltensky, I. (2008). Prólogo: Validez psicopolítica: el próximo reto para la psicología comunitaria. In M. Montero (Ed.). Introducción a la Psicología Comunitaria (pp. 13-40). Buenos Aires: Paidós.

Raffestin, C. (1980/1993). Por uma geografia do poder. São Paulo: Ática.

Raffestin, C. (1986). Ecogenèse territoriale et territorialité. In F. Auriac \& R. Brunet (Eds.), Espaces, jeux et enjeux (pp. 175185). Paris: Fayard \& Fondation Diderot.

Rozas, G. (1999). Estrategias de superación de la pobreza y gestión territorial. Intervención Psicosocial, 8(1), 63-71.

Sack, R. (1986). Human territoriality. Its Theory \& History. Cambridge: Cambridge University Press.

Santos, M. (1990). Por una geografia nueva. Madrid: Espasa Calpe.

Santos, M. (1994). El retorno del territorio. In M. Santos, M. Souza, \& M. Silveira (Orgs.), Territorio. Globalização e fragmentação (pp.15-20). São Paulo: Hucitec.

Santos, M. (2000). La naturaleza del espacio. Técnica y tiempo. Razón y emoción. Barcelona: Ariel.

Sassen, S. (2003). Contrageografias de la globalización. Género y ciudadanía en los circuitos transfronterizos. Madrid: Traficantes de sueños.

Sawaia, B. (2006). Prefacio. In M. Montero (Ed.), Hacer para transformar. El método en la Psicología Comunitaria (pp. 15-18). Buenos Aires: Paidós.

Schejtman, A. \& Berdegué, J. A. (2004). Desarrollo Rural Territorial. Temas y Debates Rurales, 1, 1-54. Acesso em 9 de outubro, 2015, em http://www.rimisp.org/wpcontent/files_mf/1363093392schejtman_y_berdegue2004 desarrollo territorial_rural 5 rimisp_CArdumen.pdf

Schneider, S. \& Peyré Tartaruga, I. (2006). Territorio y enfoque territorial: de las referencias cognitivas a los aportes aplicados al análisis de los procesos sociales rurales. In M. Manzanal, G. Neiman, \& M. Lattuada (Orgs.), Desarrollo Rural. Organizaciones, Instituciones y Territorio (pp. 71102). Buenos Aires: CICCUS.

Silveira, M. L. (2011). El desarrollo y sus lógicas en disputa en territorios del norte argentino. Biblio $3 W$. Revista
Bibliográfica de Geografía y Ciencias Sociales (on line), 16(939). Acesso em 05 de outubro, 2015, em http://www. ub.es/geocrit/b3w-939.htm.

Souza, M. L. (1995). O território: sobre espaço e poder, autonomia e desenvolvimento. In I. Castro et al. (Orgs.), Geografia: conceitos e temas (pp. 77-116). Rio de Janeiro: Bertrand Brasil.

Vidal,A. S. (1991). Psicología Comunitaria. Bases conceptuales y operativas. Métodos de Intervención. Barcelona: PPU.

Wiesenfeld, E. (2006). El rescate de las comunidades en el marco de la Globalización. Athenea Digital, 9, 46-57.

Zusman, P. (2002). Milton Santos: Su legado teórico y existencial (1926-2001). Documents d'Anàlisi Geogràfica, 40, 205-219.

\section{Agências de fomento}

Consejo Nacional de Investigaciones Científicas y Técnicas - CONICET; Universidad Nacional de Rio Negro, Argentina.

Submissão em: 03/11/2015

Revisão em: 19/05/2016

Aceite em: 18/07/2016

Santiago Conti es Becario doctoral CONICET. IIDyPCaCONICET/UNRN. Doctorando en Psicología por la Universidad de Buenos Aires (UBA). Magíster en Psicología Comunitaria (UChile). Licenciado en Psicología por la UBA.

Dirección: Universidad Nacional de Río Negro. Mitre 630. CP 8400 - San Carlos de Bariloche/Río Negro, Argentina. E-mail: santiago.conti@gmail.com 